\title{
Applying the precautionary principle to breast cancer screening: implications to public health
}

\author{
Aplicando o princípio da precaução ao rastreamento \\ do câncer de mama: implicações para a \\ saúde pública
}

\author{
Aplicando el principio de precaución para la \\ detección del cáncer de mama: implicaciones \\ para la salud pública
}

\author{
Charles Dalcanale Tesser 1 \\ Armando Henrique Norman 2 \\ Juan Gérvas ${ }^{3}$
}

doi: 10.1590/0102-311X00048319

Preventive interventions can potentially produce great harms to the individual health. Quaternary prevention (P4) is a balanced initiative to avoid unnecessary medicalization and iatrogenesis, such as overdiagnosis and overtreatment 1. P4 is defined as an action taken to identify people at risk of overmedicalization, to protect them from the excesses of biomedical interventions, and to offer ethically acceptable alternatives 2. This article discusses the Precautionary Principle (PP) to strengthen P4 when dealing with additive preventive measures such as breast cancer screening. According to Geoffrey Rose 3, additive preventive measures are generally professional-led interventions that are alien to human ecology, economy, and physiology. These include drugs, vaccines and other biological, physical, and chemical products. Additive preventive measures can produce harm without potential benefit since most individuals are asymptomatic (healthy) and not destined to become sick in the future. Consequently, additive preventive measures cannot be considered safe and policymakers are accountable for providing evidence of their net benefit.

This context is different from reductive preventive measures. Rose 3 (p. 94) defines reductive preventive measures as "removing or reducing some unnatural exposure in order to restore a state of biological normality". The aim of reductive preventive measures is to diminish artificial exposures to the individual and population health. This implies changes in ways of living that are known to be pathogenic or to carry greater health risk. By restoring biological normality to the individuals - defined as "conditions to which we are thought to be genetically adapted through our evolutionary history" 3 (p. 94) -, reductive preventive measures can enhance individual health. In clinical settings, it refers to guidance and counselling to reduce sedentary behaviour, smoking, obesity, etc. In public health and social organization, it focusses on reducing economic, social disparities 4, and promoting other health activities. Reductive preventive measures are safe, having no or minimal potential harm to people's health.

The distinction between additive and reductive preventive measures is a watershed within the universe of prevention. It offers an operational framework that facilitates the implementations of reductive preventive initiatives, while simultaneously increases the safety thresholds upon additive preventive measures. The safety, technical, and bioethical requirements to approve an additive preventive measure are greater due to their embedded potential harms. As Rose 3 (p. 94) remarks, "there can be no prior presupposition of safety, and hence the required evidence of benefit and (particularly) safety must be more stringent".
1 Departamento de Saúde Pública, Universidade Federal de Santa Catarina, Florianópolis, Brasil. 2 Departamento de Clínica Médica, Universidade Federal de Santa Catarina, Florianópolis, Brasil. 3 Departamento de Salud Internacional, Escuela Nacional de Sanidad, Madrid, España.

Correspondence A. H. Norman Departamento de Clínica Médica, Universidade Federal de Santa Catarina. Campus Reitor João David Ferreira Lima s/n, Trindade, Florianópolis, SC 88040-900, Brasil.

ahnorman@hotmail.com 


\section{The Precautionary Principle}

The PP emerged in the 1970s in Germany to address ecological issues. The belief was that governments and regulatory agencies should anticipate potential harms and prevent them from occurring 5 . The PP is applied "when an activity raises threats of harm to human health or the environment... even if some cause and effect relationships are not fully established scientifically" 6 (p. 871).

The PP fits into a wide ethical perspective. The aim is to develop public health protective measures in face of scientific uncertainties 7. The PP is concerned with preventive measures necessary to avoid the harmful consequences of an intervention 8 . This differs from the risk-management approach that seeks to establish tolerable harm-thresholds for an intervention. Public health and preventive medicine tend to operate on the reactive principle. According to Kriebel 9 (p. 872), the reactive principle requires "high degree of certainty of harm before preventive action is taken". To change from a reactive to a precautionary principle stance, the PP's four main components should guide decision-making processes 6 :

(1) Preventive measures must be adopted to avoid harmful consequences of an intervention in face of scientific uncertainty;

(2) Intervention proponents are accountable for providing the evidence of its effectiveness and safety;

(3) Policymakers should first explore harmless alternatives;

(4) The decision-making process should increase public participation.

The PP has already been explored in medical context. For instance, Wilson et al. 10 discuss its application in blood transfusion. The PP was then applied to protect patients from acquiring bloodtransmitted diseases via blood transfusion at a time of scientific uncertainty. According to Martuzzi 5 , the PP has in part embraced the bioethical principle of non-maleficence, commonly applied in clinical care. However, clinical care is an ethically complex situation and substantially different from prevention 11. Thus, applying the PP when taking care of patients with more serious illnesses can have the opposite effect 12 . This is not the case of PP in additive preventive measures, when patients are asymptomatic, i.e., healthy. In these situations, the principle of non-maleficence should prevail 13.

Goldstein 7 argues that the PP should be considered in public health initiatives. In this regard, preventive additive measures should be the locus for employing PP more systematically. However, PP has received little attention when considered common preventive activities, performed at primary health care through public health programs such as vaccinations, screening and the use of preventive-drugs. Additionally, assessment of current preventive recommendations is also embedded in PP concept. Advancements in scientific knowledge and evidence may indicate that a common practice is no longer safe to be recommended. For instance, hormone replacement therapy as primary prevention for cardiovascular events and osteoporosis has probably caused more harm than good 14 . This might not have been the case if the PP had been considered. Thus, PP is an important conceptual-tool to operationalize $\mathrm{P} 4$. Nevertheless, several additive preventive measures are being routinely performed on millions of people.

\section{Evidence on breast cancer screening}

After decades of major technological developments in mammography, computation, statistics and therapy, new clinical trials and observational studies have dramatically changed the breast cancer screening context (Box 1): (a) meta-analyses of clinical trials have only showed 10\% to 15\% reduction in breast cancer mortality, being nil in the best clinical trials. This means an insignificant absolute risk reduction in breast cancer mortality; (b) reduction in the incidence of severe forms of the disease has not been observed in the screened population, as screening programmes tend to select slower or less aggressive forms of disease (length time bias); (c) high occurrence of overdiagnosis and overtreatment: for every woman who has her death avoided from breast cancer, about three are diagnosed with a cancer that would never have become life-threatening; (d) screened women have an increased relative mortality risk from heart disease (27\%) and lung cancer (78\%) due to radiotherapy; and (e) studies comparing screened versus non-screened populations showed no difference in breast cancer mortality. Most declines in breast cancer mortality seem to stem from therapeutic improvements rather than screening programmes. 
Box 1

Changes on breast cancer screening evidence.

\begin{tabular}{|c|c|}
\hline Outcomes & Supporting literature \\
\hline Impact on mortality & $\begin{array}{l}\text { - Gøtzsche PC, Jørgensen KJ. Screening for breast cancer with mammography. } \\
\text { Cochrane Database Syst Rev 2013; (6):CD01877. }\end{array}$ \\
\hline \multirow[t]{2}{*}{$\begin{array}{l}\text { Impact on aggressive } \\
\text { tumour }\end{array}$} & $\begin{array}{l}\text { - Autier P, Boniol M, Middleton R, Doré J-F, Héry C, Zheng T, et al. Advanced breast } \\
\text { cancer incidence following population-based mammographic screening. Ann Oncol } \\
2011 ; 22: 1726-35 \text {. }\end{array}$ \\
\hline & $\begin{array}{l}\text { - Welch HG, Prorok PC, O'Malley AJ, Kramer BS. Breast-cancer tumor size, } \\
\text { overdiagnosis, and mammography screening effectiveness. N Engl J Med 2016; } \\
\text { 375:1438-47. }\end{array}$ \\
\hline \multirow[t]{4}{*}{$\begin{array}{l}\text { Overdiagnosis and } \\
\text { overtreatment }\end{array}$} & $\begin{array}{l}\text { - Bleyer A, Welch HG. Effect of three decades of screening mammography on } \\
\text { breast-cancer incidence. N Engl J Med 2012; 367:1998-2005. }\end{array}$ \\
\hline & $\begin{array}{l}\text { - Miller AB, Wall C, Baines CJ, Sun P, To T, Narod SA. Twenty-five year follow-up for } \\
\text { breast cancer incidence and mortality of the Canadian National Breast Screening } \\
\text { Study: randomised screening trial. BMJ 2014; 348:g366. }\end{array}$ \\
\hline & $\begin{array}{l}\text { - Autier P, Boniol M, Koechlin A, Pizot C, Boniol M. Effectiveness of and } \\
\text { overdiagnosis from mammography screening in the Netherlands: population-based } \\
\text { study. BMJ 2017; 359:j5224. }\end{array}$ \\
\hline & $\begin{array}{l}\text { - Cancer Research UK. NHS breast screening: helping you decide. http://www.uhs. } \\
\text { nhs.uk/Media/SUHTInternet/Services/BreastImagingUnit/NHS-Breast-Screening--- } \\
\text { helping-you-decide.pdf (accessed on 22/Apr/2018). }\end{array}$ \\
\hline $\begin{array}{l}\text { Exposure to other life- } \\
\text { threatening diseases }\end{array}$ & $\begin{array}{l}\text { - Gøtzsche PC, Jørgensen KJ. Screening for breast cancer with mammography. } \\
\text { Cochrane Database Syst Rev 2013; (6):CD01877. }\end{array}$ \\
\hline \multirow[t]{2}{*}{$\begin{array}{l}\text { Improvement in clinical } \\
\text { cancer treatments }\end{array}$} & $\begin{array}{l}\text { • Jørgensen KJ, Zahl P-H, Gøtzsche PC. Breast cancer mortality in organised } \\
\text { mammography screening in Denmark: comparative study. BMJ 2010; 340:c1241. }\end{array}$ \\
\hline & $\begin{array}{l}\text { - Olsen O, Gøtzsche PC. Cochrane review on screening for breast cancer with } \\
\text { mammography. Lancet 2001; 358:1340-2. }\end{array}$ \\
\hline
\end{tabular}

\section{Applying the Precautionary Principle to breast cancer screening}

The requirements for regulatory agencies appear to be consistent with the PP's second component. Their protocol requires high levels of evidence, based on clinical trials and their metanalysis, for getting the approval of medicines and other products. Considering current evidence on breast cancer screening, how would the PP guide a decision-making process? Firstly, based on PP's components one and two, the recommendation on breast cancer screening should change. The scientific uncertainty about its benefit and known potential harms warrants this measure. For instance, the U.S. Preventive Services Task Force 15 should downgrade its recommendation on breast cancer screening from "B the net benefit is moderate to substantial" to " $\mathrm{C}$ - the benefit is small", or even " $\mathrm{D}$ - no net benefit or the harms outweigh the benefits" in accordance with the best clinical trials and observational studies (Box 1) and as proposed by the Swiss Medical Board 16. Secondly, component three would require an alternative approach to breast cancer screening. This includes preventive measures aiming at overall health improvements and strategies to boost timely diagnosis through strong primary health care services. Finally, component four (i.e., public participation) should consider two dimensions: 
(1) institutional and scientific preventive committees; and (2) service delivery. The former should have a wider socialization process about their recommendations to improve informed decision to policymakers. The broad public and scientific consultation process on breast cancer screening in France stands out as an example of such initiative 17. Additionally, rigorously quality-assured and evidencebased screening programmes should inform their target population about the potential harms and benefits of screening. Educational and decision-aiding materials should not biasedly promote screening but inform about its pros and cons 18 . This would help to empower women and their clinicians to build shared decisions. On the service delivery, health professionals and patients need to improve their statistical literacy ${ }^{19}$, a prerequisite for active participation and informed decision. Few patients understand the basic health statistics. This partial information tends to permeate clinicians-patients decision-making processes. In this regard, it is necessary to have a strict control on vested economic interests in producing and processing biomedical evidence 20,21 .

\section{Conclusion}

Public health needs to highlight the distinctive nature of additive preventive measures and apply the PP to guide P4 within preventive initiatives. Although there is little disagreement that non-maleficence should prevail in additive preventive measures, reality shows otherwise. Vested interests and conceptual misunderstanding around preventive initiatives are producing serious harms to many people, as exemplified by overdiagnosis and overtreatment phenomenon 22 . Thus, conceptual developments on prevention and research need to be fostered to guide policymakers in the production of institutional guidelines. This would build legitimacy and systematic application for the PP to additive preventive measures.

\section{Contributors}

C. D. Tesser contributed to the article design and preparation of the first version. A. H. Norman and J. Gervas contributed to the critical review of the intellectual content and the writing of the article.

\section{Additional informations}

ORCID: Charles Dalcanale Tesser (0000-00030650-8289); Armando Henrique Norman (00000002-5267-7377); Juan Gérvas (0000-0002-78025457).
1. Norman AH, Tesser CD. Quaternary prevention: a balanced approach to demedicalisation. Br J Gen Pract 2019; 69:28-9.

2. Bentzen N. Wonca dictionary of general/family practice. Copenhagen: Wonca International Classification Committee; 2003.

3. Rose G. The strategy of preventive medicine. Oxford: Oxford University Press; 1992.

4. Wilkinson R, Pickett K. The spirit level: why equality is better for everyone. London: Penguin UK; 2010.

5. Martuzzi M. The precautionary principle: in action for public health. Occup Environ Med 2007; 64:569-70.

6. Kriebel D, Tickner J, Epstein P, Lemons J, Loechler EL, Quinn M, et al. The precautionary principle in environmental science. Environ Health Perspect 2001; 109:871-6.

7. Goldstein BD. The precautionary principle also applies to public health actions. Am J Public Health 2001; 91:1358-61.

8. Guggenheim R. Bringing the planet into the generalist practice: a form of preventive care. Lancet Planet Health 2018; 2:e200-1. 
9. Kriebel D. The reactionary principle: inaction for public health. Occup Environ Med 2007; 64:573-4.

10. Wilson K, Atkinson KM, Fergusson DA, Brown A, Forster A, Murphy MSQ, et al. Problems with precaution: the transfusion medicine experience. J Risk Res 2018; 2017:1-13.

11. Tesser CD, Norman AH. Differentiating clinical care from disease prevention: a prerequisite for practicing quaternary prevention. Cad Saúde Pública 2016; 32:e00012316.

12. Foidart JM. The precautionary principle and the obligation of medical action. Bull Acad Natl Med 2000; 184:937-43.

13. Smith CM. Origin and uses of primum non nocere - above all, do no harm! J Clin Pharmacol 2005; 45:371-7.

14. Sackett DL. The arrogance of preventive medicine. CMAJ 2002; 167:363-4.

15. U.S. Preventive Services Task Force. Final Update Summary: breast cancer: screening. https://www.uspreventiveservicestaskforce. org/Page/Document/UpdateSummaryFinal/ breast-cancer-screening (accessed on 23/Apr/ 2018).

16. Biller-Andorno N, Jüni P. Abolishing mammography screening programs? A view from the Swiss Medical Board. N Engl J Med 2014; 370:1965-7.
17. Barratt A, Jørgensen KJ, Autier P. Reform of the National Screening Mammography Program in France. JAMA Intern Med 2018; 178:177.

18. Gøtzsche PC, Hartling OJ, Nielsen M, Brodersen J. Screening for breast cancer with mammography - leaflet. Copenhagen: The Nordic Cochrane Centre; 2012.

19. Malhotra A, Maughan D, Ansell J, Lehman R, Henderson A, Gray M, et al. Choosing wisely in the UK: the Academy of Medical Royal Colleges' initiative to reduce the harms of too much medicine. BMJ 2015; 350:h2308.

20. Kelly MP, Heath I, Howick J, Greenhalgh T. The importance of values in evidence-based medicine. BMC Med Ethics 2015; 16:69.

21. Gøtzsche PC. Deadly medicines and organised crime: how Big Pharma has corrupted healthcare. London: Radcliffe Publishing; 2013.

22. Heath I. Overdiagnosis: when good intentions meet vested interests. BMJ 2013; 347:f6361. 